\title{
Numerical analysis of hydrodynamic interaction between the linear waves of Caspian Sea and Amirkabir semi-submersible drilling platform
}

\author{
Rahmatollah Ghajar" and Seyed Mohammad Navid Ghoreishi
}

Mechanical Properties Lab, Faculty of Mechanical Engineering, K.N. Toosi University of Technology, Tehran, Iran

\begin{tabular}{ll}
\hline A R T I C L E I N F O & A B S T R A C T \\
\cline { 2 - 3 } $\begin{array}{l}\text { Article history: } \\
\text { Received March 20, 2013 }\end{array}$ & $\begin{array}{l}\text { Semi-submersible drilling platforms are huge bulk structures for extracting the oil products } \\
\text { feceived in Revised form } \\
\text { feptember, 14, 2013 }\end{array}$ \\
$\begin{array}{l}\text { for determining the loads applied to the semi-submersible drilling platforms. The diffraction } \\
\text { theory should be used for evaluating the hydrodynamic interactions between the platform and }\end{array}$ \\
Available online & the sea waves. In this theory, the Laplace equation is solved by considering the boundary \\
18 September 2013 & conditions of the diffraction theory. In this paper, after a brief description of the diffraction \\
Keywords: & theory, the hydrodynamic interactions between the Iran's Amirkabir semi-submersible drilling \\
Diffraction theory & platform and the regular linear waves of Caspian Sea is investigated numerically using \\
Hydrodynamic analysis & boundary element method in the ANSYS/AQWA software. The induced waves exciting forces \\
Semi-submersible drilling platform & and moments with different wave heading angles are estimated for six degrees of freedom \\
Regular waves & relative to the waves frequencies using the diffraction theory. The performed hydrodynamic \\
analysis is also validated with the previous works performed for Spar platforms.
\end{tabular}

\section{Introduction}

Nowdays the discovery of the oil and gas resources in the seas has been focused to the great depths and the use of fixed platforms (which are limited to depths of 360 to $450 \mathrm{~m}$ ) is not applicable for these situations. Hence, the use of new submersible and floating platforms such as tension leg platforms (TLP), semi-submersible platforms, spar platforms and etc. which are suitable for great depths is rapidly growing (Wilson, 2003, Gerwick, 2002). The first step for designing the semisubmersible platforms is their hydrodynamic analysis and estimating the induced forces from the sea waves to the platforms. In other words, estimating the critical wave is the key issue for design of semi-submersible platforms. Since this type of platforms is among the huge offshore structures, it is necessary to employ the diffraction theory for determining the applied waves to the platform and analyzing its hydrodynamic response. A review of literature shows that Mendes et al. (2003)

* Corresponding author.

E-mail addresses: ghajar@kntu.ac.ir (R. Ghajar)

(C) 2013 Growing Science Ltd. All rights reserved. doi: $10.5267 /$ j.esm.2013.09.004 
investigated the forces induced by the sea waves to the offshore structures using numerical analyses. They used Morrison's equations for determining the interaction forces between the water and the structure. Ran et al. (1996) analyzed the mooring system of spar platforms subjected to linear and regular sea waves using Morrison's equations. However, it is now widely accepted that for huge offshore structures the use of Morrison's equations may result significant errors in estimating the induced forces and for such structures it is better to use the diffraction theory. Accordingly, Ketabdari and Mirzaei Sefat (2011) recently studied the dynamic behavior of a Spar platform using finite difference numerical method by employing the diffraction theory. They obtained the exciting forces induced from the sea waves to the spar platform in six degrees of freedom. Liu et al. (2012) studied wave diffraction and radiation by a submerged sphere in infinite water depth analytically. Teng and Kato $(1999,2002)$, determined the applied forces to a floating cylinder induced by the interactions between the second and third order regular linear waves and the cylinder using the diffraction theory in the frequency domain and by analyzing a finite difference model. Also, using boundary element method, Ray (2000) determined numerically the response amplitude operator, the applied forces and moments in the frequency domain and for six degree of freedom for different models such as cylinders and spheres. Mohseni Armak and Gharebaghi (2012) studied the effect of heave plates on the hydrodynamic response of Iran's Amirkabir semi-submersible drilling platform. They concluded that adding the heave plates improve the hydrodynamic response of the platform especially its vertical movement and rotating about the lateral axes. In this paper, the induced waves exciting forces and moments with different wave heading angles are estimated from the regular and linear waves of the Caspian Sea on the Amirkabir platform by employing the diffraction theory.

\section{Induced forces from the sea waves on the platforms}

The sea waves apply significant dynamic forces to the offshore and marine structures. Thus accurate estimations of induced sea forces are very important parameters for designing such structures. The waves in real situations are non-linear and their forces are variable with time but they are generally assumed to be simple and harmonic. For small and slender structures, the wave parameters remain nearly constant before and after impact to the structure because of the small size of structure relative to the wave length. However, when the size of structure becomes larger, variations of wave parameters are not negligible, and the structure affects the wave field and may introduce some disturbances. Thus, diffraction of the wave is expected after passing from the huge offshore structures and hence the influence of such effect for estimating the induced forces of waves should be taken into

account. For such situations the Morisson's equation is not valid and in general when the diameter of structure to the wave length is more than 0.2 (such that the case of Amirkabir semi-submersible drilling platform) the diffraction theory should be used for analyzing the hydrodynamic response of the structure. For huge platforms it is often assumed that the fluid is inviscid and incompressible, the motion is irrational and periodic and hence the flow field can be depicted by a velocity potential $\emptyset(x, y, z)$. For such conditions the Laplace governing equation can be written as follows (Chakrabarti. 1987):

$\nabla^{2} \emptyset=\frac{\partial^{2} \emptyset}{\partial x^{2}}+\frac{\partial^{2} \emptyset}{\partial y^{2}}+\frac{\partial^{2} \emptyset}{\partial z^{2}}=0$

where $x, y, z$, are the Cartesian system coordinates and $\varnothing$ is the potential function of velocity. In the diffraction theory the potential function of a linear wave can be divided to three parts namely: (i) incident wave $\left(\emptyset_{I}\right)$, (ii) diffraction wave $\left(\emptyset_{\mathrm{D}}\right)$ and (iii) radiation wave $\left(\emptyset_{\mathrm{R}}\right)$ as:

$\emptyset=\emptyset_{I}+\emptyset_{\mathrm{D}}+\emptyset_{\mathrm{R}}$

\section{Dynamic analysis}

For dynamic analysis of the system, it is necessary first to obtain the added mass, damping and stiffness coefficients and also the forces applied to the body for all of the degrees of freedom. These 
coefficients should then be replaced into Eq. (3) to study the dynamic response of the body (Mirzaye Sefat \& Ketabdary (2007)):

$(m+M) \ddot{X}+C \dot{X}+K X=\mathrm{F}_{w}$,

where $\mathrm{m}$ is the added mass coefficient, $\mathrm{M}$ is the mass of body, $\mathrm{C}$ and $\mathrm{K}$ are the damping and stiffness coefficients, respectively and $F_{\mathrm{w}}$ is the applied external force. The mentioned coefficients have different values in any free degrees of freedom. The applied loads are often determined in terms of the amount of pressure applied to the body, which can be obtained from Bernoli's equation as follows:

$P(t)+\rho \frac{\partial \emptyset}{\partial t}+\frac{1}{2} \rho|\nabla \emptyset|^{2}+\rho g z=C(t)$

where $\mathrm{P}$ is the pressure, $\rho$ and $\mathrm{g}$ are the density of fluid and the gravity acceleration, respectively. $\mathrm{C}(\mathrm{t})$ is an arbitrary value which can be assumed equal to zero. For assuming the waves as linear waves, the pressure should be also considered as linear. This can be done by ignoring the hydrostatic term and the second order dynamic effects of waves. Thus, the applied force can be determined from:

$F(t)=\iint_{S} P(t) \cdot n \cdot d s=\iint_{s} \rho \cdot \frac{d \emptyset}{d t} \cdot n \cdot d s$,

In Eq. (5), $\mathrm{n}$ is the normal vector of the surface and if the potential function is written in terms of incident, diffraction and radiation waves, one gets:

$F(t)=\operatorname{Re}\left\{\iint_{s} i \rho \omega \cdot e^{i \omega t} \cdot n \cdot\left(a \widehat{\phi_{I}}+a \widehat{\phi_{D}}+\widehat{x_{n}} \cdot \widehat{\phi_{R}}\right) \cdot d s\right\}$

Eq. (6) can be also rewritten as:

$F(t)=\operatorname{Re}\left\{\hat{F} \cdot e^{i \omega t}\right\}=\operatorname{Re}\left\{a \cdot\left(\hat{F}_{I}+\hat{F}_{D}\right) \cdot e^{i \omega t}+\bar{x}_{n} \hat{F}_{R} \cdot e^{i \omega t}+F_{\text {Hydrostatic }}\right\}$

where, $\hat{F}$ is the amplitude of total force. Also, $a . \hat{F}_{I}$ and $a . \hat{F}_{D}$ are the amplitudes of Froude-Krylove and diffraction loads and thus $a .\left(\hat{F}_{I}+\hat{F}_{D}\right)$ is the amplitude of the total force applied to the structure. The load amplitudes of incident, diffraction and radiation waves can be also obtained from:

$\widehat{F}_{I}=i \omega \rho \cdot \iint_{s} \widehat{\emptyset}_{I} \cdot d s$

$\hat{F}_{D}=i \omega \rho \cdot \iint_{s} \widehat{\phi}_{D} \cdot d s$

$\widehat{F}_{R}=i \omega \rho \cdot \iint_{S} \widehat{\emptyset}_{R} \cdot d s$

\section{Verification of numerical modeling for hydrodynamic analysis}

Since the main objective of this paper is to analyze the hydrodynamic response of a real huge semisubmersible platform (i.e. the Amirkabir platform) using numerical modeling, first it is necessary to verify the used modeling process. Hence, before modeling and analyzing the Amirkabir platform, the modeling process was verified using the previous similar works performed for Spar platforms (Ray, 2000; Ketabdari \& Mirzaei Sefat, 2011). Ray (2000) used MOSES and WAMIT codes for modeling of a Spar platform using boundary element method. Ketabdari and Mirzaei Sefat (2011) also analyzed a platform numerically by means of a finite difference method. While the finite difference method uses volumetric and three dimensional meshes (and hence a large number of elements may be used for modeling a huge structure), only the surface of a structure is needed to be meshed in the boundary element method. Consequently, this method is more suitable for numerical modeling of huge 
structures such as offshore platforms. Thus, the boundary element method is employed for analyzing the hydrodynamic response of the platform. Geometrical specifications of the modeled Spar platform are listed in Table 1.

Table 1

Geometrical specifications of the modeled Spar platform.

\begin{tabular}{cc}
\hline Platform specification & Value \\
\hline Height & $400 \mathrm{~m}$ \\
Diameter & $40 \mathrm{~m}$ \\
Operation draught & $200 \mathrm{~m}$ \\
Weight & $256011 \mathrm{ton}$ \\
\hline
\end{tabular}

Accordingly a Spar platform with the mentioned specifications in Table 1 is modeled in ANSYS/AQWA software and the induced forces from the sea waves are computed. Fig. 1, shows the applied wave to the Spar platform which is modeled in ANSYS/AQWA.

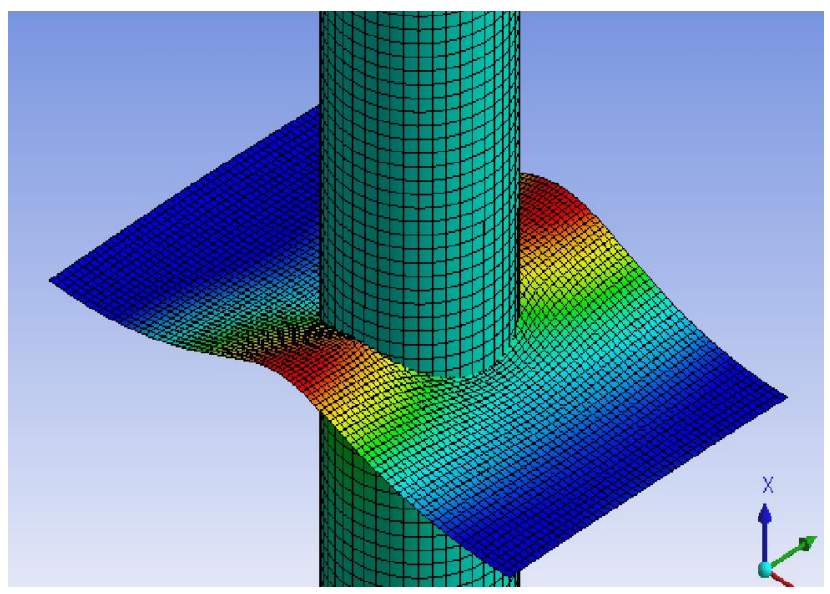

Fig. 1. A typical wave applied to the Spar platform

Fig. 2 compares the applied sea wave force in the $\mathrm{x}$ direction (i.e. surge direction) computed in this research with the previous works. The good agreements that are seen between the numerical results of this study with the results reported by Ray (2000) and Ketabdari and Mirzaei Sefat (2011) indicate the accuracy and validity of the employed method of this research. Similar consistencies were also obtained for the forces and moments in other degrees of freedoms.

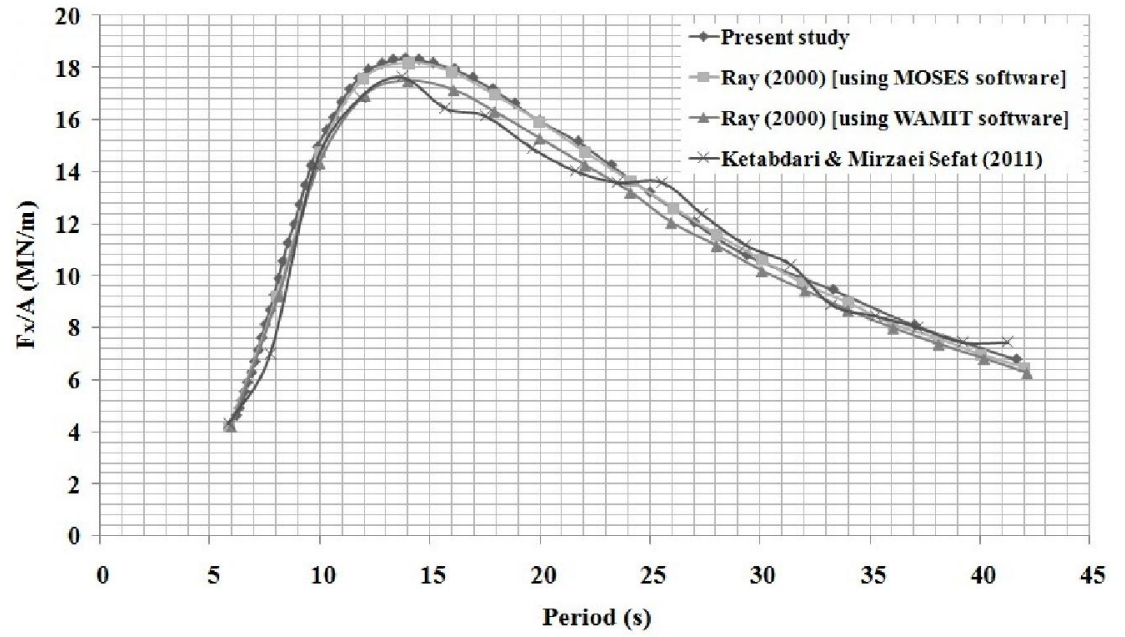

Fig. 2. Comparison of wave exciting forces applied to a typical Spar platform in the surge direction 


\section{Modeling of the Amirkabir semi-submersible drilling platform}

The Amirkabir semi-submersible drilling platform which is designed and manufactured for discovery and extraction of oil at depth of $1000 \mathrm{~m}$ of the Caspian Sea has the following main specifications (Mohseni Armak \& Gharebaghi, 2012):

Table 2. Specifications of the Amirkabir platform.

\begin{tabular}{ll}
\hline Diameter of columns & $12.9 \mathrm{~m}$ \\
Diameter of brace & $2 \mathrm{~m}$ \\
\hline Longitudinal distance of columns & $54.72 \mathrm{~m}$ \\
Transverse distance of columns & $54.72 \mathrm{~m}$ \\
\hline Height to lower deck & $28.5 \mathrm{~m}$ \\
Operation draught & $19.5 \mathrm{~m}$ \\
Height to upper deck & $36.5 \mathrm{~m}$ \\
Breadth outside pontoon & $73.4 \mathrm{~m}$ \\
Length of pontoon & $80.56 \mathrm{~m}$ \\
Breadth of pontoon & $18.68 \mathrm{~m}$ \\
Height of pontoon & $7.5 \mathrm{~m}$ \\
Total weight of platform & $28621 \mathrm{ton}$ \\
\hline
\end{tabular}

Environmental specifications of the Caspian Sea for a period of 100 years have also been reported by Mohseni Armak \& Gharebaghi (2012) as:

Table 3. Environmental characteristics of the Caspian Sea for period of 100 years (Mohseni Armak \& Gharabaghi, 2012)

\begin{tabular}{cccc}
\hline $\begin{array}{c}\text { Orientation relative to } \\
\text { north direction (degree) }\end{array}$ & $\begin{array}{c}\text { Probability of } \\
\text { occurrence }(\%)\end{array}$ & $\begin{array}{c}\text { Height of nominal } \\
\text { wave }(\mathrm{m})\end{array}$ & Period (s) \\
\hline 0 & 24 & 10.50 & 11.53 \\
45 & 14 & 10.20 & 10.45 \\
90 & 13 & 9.30 & 10.17 \\
135 & 7 & 8.10 & 8.83 \\
180 & 7 & 7.35 & 8.24 \\
225 & 8 & 8.25 & 8.95 \\
270 & 10 & 8.85 & 9.85 \\
315 & 18 & 10.05 & 11.06 \\
\hline
\end{tabular}

According to the data of Table 3, the most critical case i.e. the wave with zero degree relative to north direction (with height of $10.5 \mathrm{~m}$ and period of $11.53 \mathrm{~s}$ ) is chosen for applying the wave loads to the Amirkabir platform. The occurrence probability of such a wave is more than the other types of waves in the Caspian Sea. The density of the Caspian Sea water is considered as $1025 \mathrm{~kg} / \mathrm{m}^{3}$. For performing the hydrodynamic analysis it is necessary that the mass momentum inertias of the whole platform about its gravity centroid to be known. The ABAQUS code was employed for determining the required momentum inertias. The following properties was assumed for the platform made of steel material: $\mathrm{E}=200 \mathrm{GPa}, \rho=7860 \mathrm{Kg} / \mathrm{m}^{3}$. Table 4, presents the determined mass momentum inertias for the Amirkabir platform.

Table 4. Mass momentum inertias of the whole Amirkabir semi-submersible drilling platform about its gravity centroid

\begin{tabular}{llll}
\hline Mass momentum inertias & $\mathbf{I}_{\mathbf{x x}}$ & $\mathbf{I}_{\mathbf{y y}}$ & $\mathbf{I}_{\mathbf{z Z}}$ \\
\hline Value $\left(\mathrm{Kg} \cdot \mathrm{m}^{2}\right)$ & $2.24 \times 10^{10}$ & $1.99 \times 10^{10}$ & $\mathbf{3 . 1 6 \times 1 0 ^ { \mathbf { 1 0 } }}$ \\
\hline
\end{tabular}

Fig 3, shows the model of Amirkabir semi-submersible drilling platform created in ANSYS/AQWA software. 


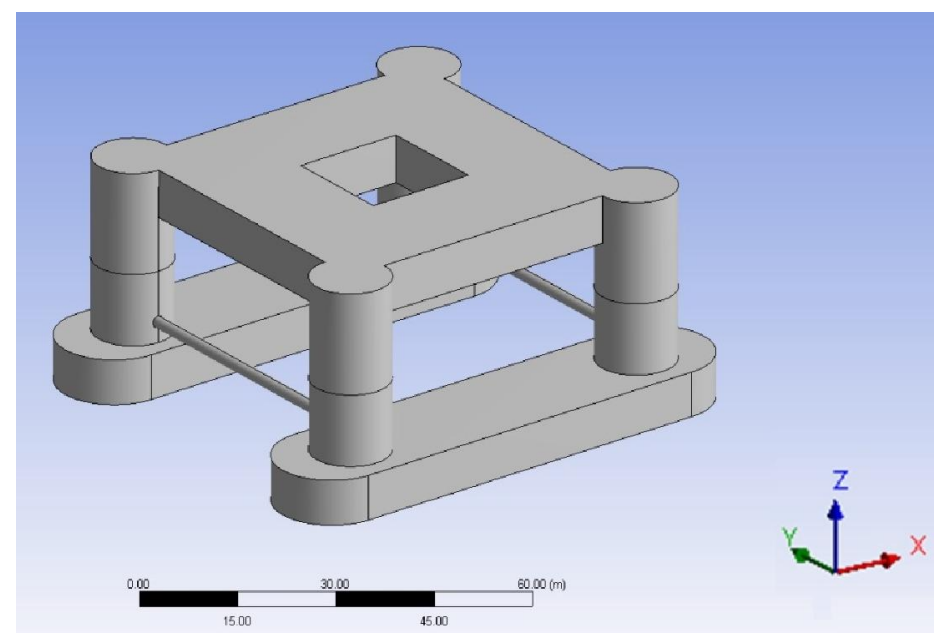

Fig. 3. The model of Amirkabir platform created in ANSYS/AQWA software.

\section{Hydrodynamic analysis of the Amirkabir platform}

In this section the interaction between the regular and linear waves of the Caspian Sea and Amirkabir platform is analyzed. The induced forces are determined for different wave frequencies impacting with directions $0^{\circ}, 30^{\circ}, 60^{\circ}$ and $90^{\circ}$ relative to the $\mathrm{x}$ axis of the platform. The boundary element method is used for numerical modeling of platform. The surfaces are meshed using a total number of 11625 elements. Fig. 4 shows the different directions of waves impacted with the platform.
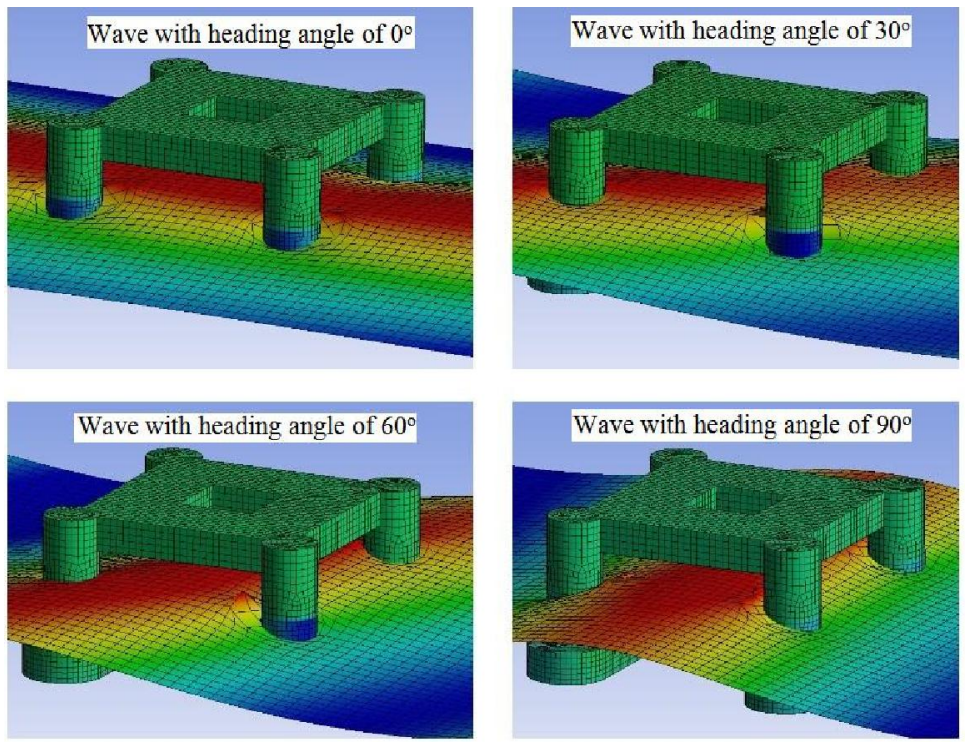

Fig. 4. Different heading angles applied from the waves to the Amirkabir platform.

The results of waves exciting forces and moments applied to the platform for six degrees of freedom are shown in Figs. 5 to 10 for 44 frequencies of the sea waves. In these Figs $\mathrm{A}$ is the amplitude of the impacted wave, $F_{x}, F_{y}$ and $F_{z}$ are the wave exciting forces applied to the platform in surge, sway and heave directions, respectively. $\mathrm{M}_{\mathrm{x}}, \mathrm{M}_{\mathrm{y}}$ and $\mathrm{M}_{\mathrm{z}}$ are also the wave exciting moments about roll, pitch and yaw axes. Using the Figs. 5 to 10, we can extract for the Caspian Sea condition and for the period of 11.53 seconds and the results are summarized in Table 5. 


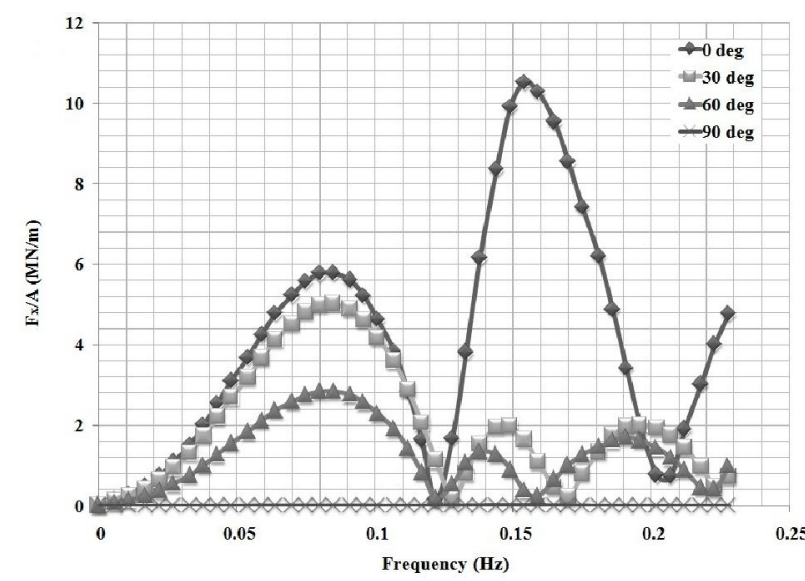

Fig. 5. Wave exciting forces applied to the Amirkabir platform in the $\mathrm{x}$ (or surge) direction for different frequencies of the waves

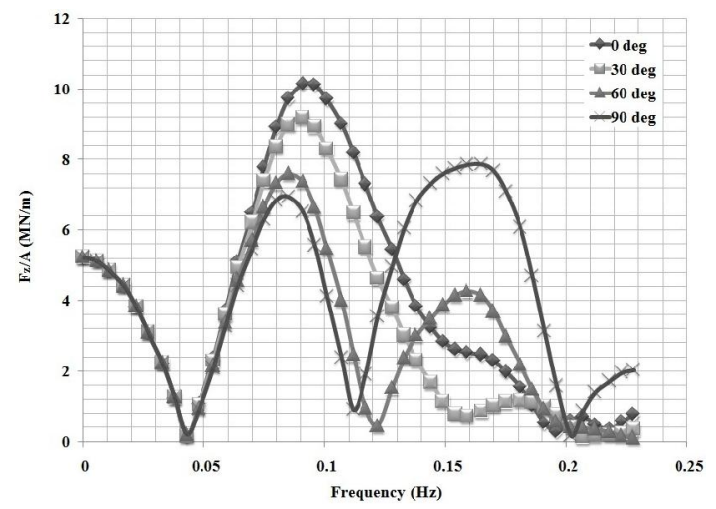

Fig. 7. Wave exciting forces applied to the Amirkabir platform in the $\mathrm{z}$ (or heave) direction for different frequencies of the waves

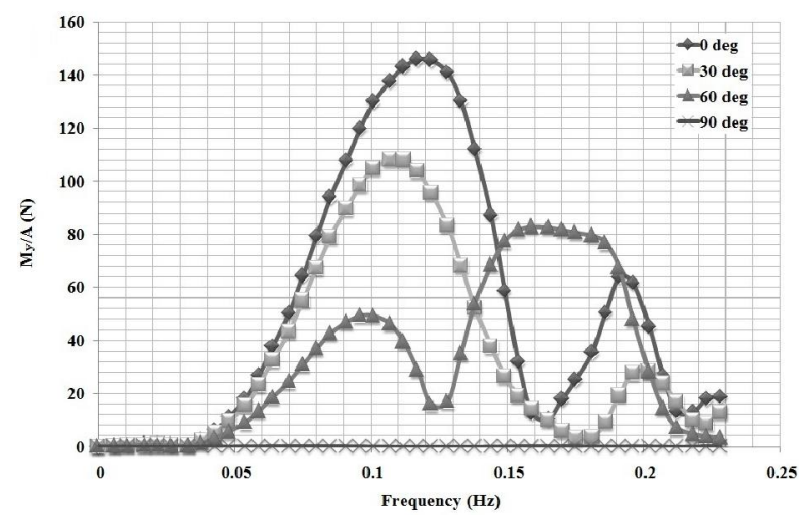

Fig. 9. Wave exciting moments applied to the Amirkabir platform in the $y$ (or pitch) direction for different frequencies of the waves.

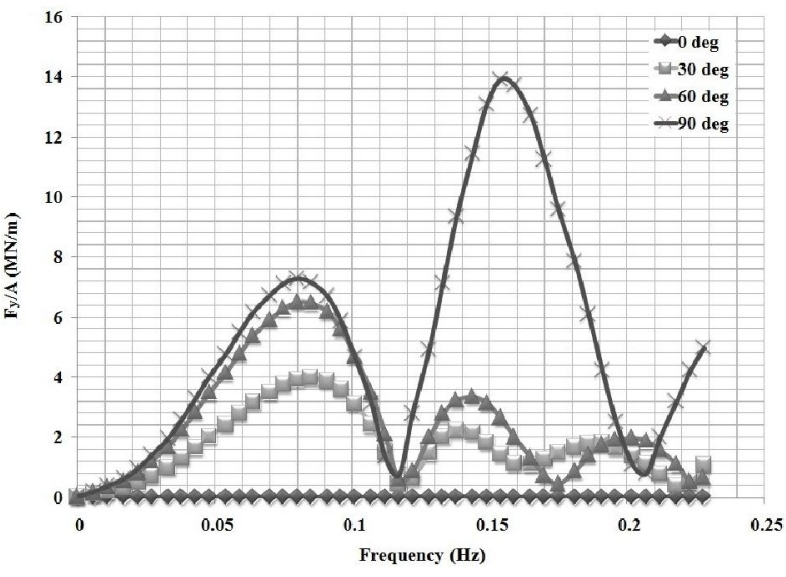

Fig. 6. Wave exciting forces applied to the Amirkabir platform in the y (or sway) direction for different frequencies of the waves

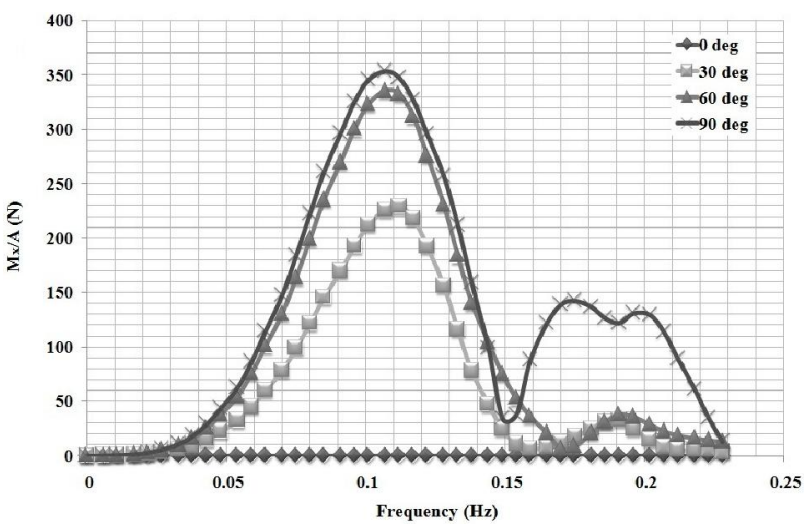

Fig. 8. Wave exciting moments applied to the Amirkabir platform in the $\mathrm{x}$ (or roll) direction for different frequencies of the waves

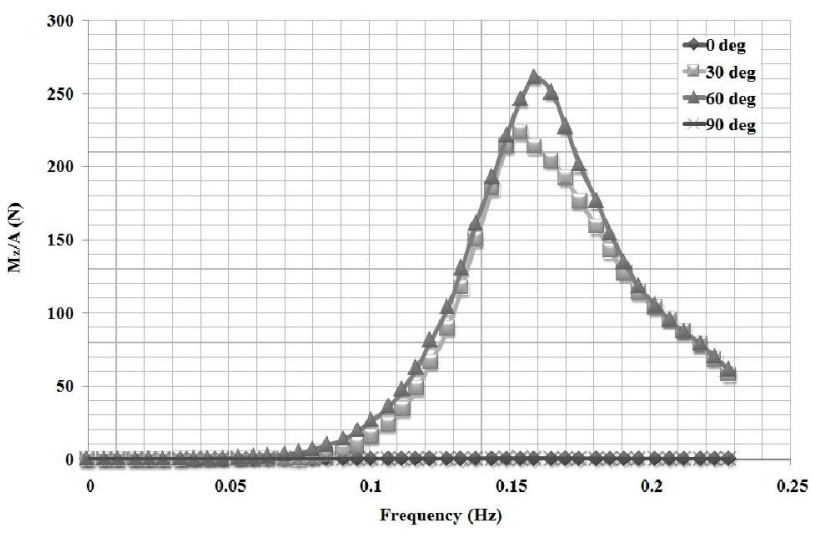

Fig. 10. Wave exciting moments applied to the Amirkabir platform in the $\mathrm{z}$ (or yaw) direction for different frequencies of the waves 
Table 5. Wave exciting force and moments applied to the Amirkabir platform with wave period of 11.53 seconds.

\begin{tabular}{|c|c|c|c|c|c|c|c|c|}
\hline $\begin{array}{l}\text { Wave Heading } \\
\text { angle (degree) }\end{array}$ & $\frac{F_{x}}{A}(M \mathbf{N} / \mathbf{m})$ & $\frac{F_{y}}{A}(M \mathbf{N} / \mathbf{m})$ & $\frac{F_{z}}{A}(\mathbf{M N} / \mathbf{m})$ & $\begin{array}{c}\text { Resultant } \\
\text { forces } \\
(\mathbf{M N} / \mathbf{m})\end{array}$ & $\frac{\boldsymbol{M}_{\boldsymbol{x}}}{\boldsymbol{A}}(\mathbf{M N})$ & $\frac{M_{y}}{A}(\mathbf{M N})$ & $\frac{M_{z}}{A}(\mathbf{M N})$ & $\begin{array}{c}\text { Resultant } \\
\text { moments } \\
(\mathbf{M N})\end{array}$ \\
\hline 0 & 5.78 & 0 & 9.73 & 11.3 & 0 & 93.7 & 0 & 93.7 \\
\hline 30 & 5.02 & 3.97 & 8.99 & 11 & 146 & 79 & 2.79 & 166 \\
\hline 60 & 2.84 & 6.47 & 7.59 & 10.4 & 235 & 24.5 & 9.76 & 239 \\
\hline 90 & 0 & 7.16 & 6.94 & 9.97 & 261 & 0 & 0 & 261 \\
\hline
\end{tabular}

It can be concluded from Table 5 that while the wave with heading angle of $0^{\circ}$ relative to the $\mathrm{x}$ axis of the platform exerts the maximum forces, the greatest moments are applied to the platform when the wave heading angle is $90^{\circ}$. This reveals that, the stress analysis of the platform subjected to different waves is also necessary in addition to the hydrodynamic interaction analysis to obtain the critical waves.

\section{Conclusion}

In this paper, the wave exciting forces and moments applied from the linear waves of the Caspian Sea to the Amirkabir semi-submersible drilling platform with different wave frequencies and wave heading angles were analyzed numerically using boundary element method in ANSYS/AQWA software. The hydrodynamic response of the platform was determined based on the diffraction theory. Extensive data presented in this research can be helpful for estimating the wave exciting loads and moments induced from various ranges of wave frequencies and heading angles in the Caspian Sea. However, due to the complex nature of coupled force-moment effects, the stress analysis of the platform is also required in addition to the hydrodynamic analyses to find the critical waves that are impacted with the platform. These analyses can be used for safe and reliable design of the semisubmersible platform structures.

\section{Reference}

Chakrabarti, S. K. (1987). Hydrodynamics of offshore structures: Mathematical theory and its applications in structures.

Gerwick, C. (2002). Construction of marine and offshore structures. CRC Press.

Ketabdari, M.J., \& Mirzaei Sefat, S. (2011). Dynamic analysis of interaction between linear waves and spar floating platform. Journal of Civil and Surveying Engineering, 45(1), 45-52.

Liu, Y. Y., Teng, B., Cong, P. W., Liu, C. F., \& Gou, Y. (2012). Analytical study of wave diffraction and radiation by a submerged sphere in infinite water depth. Ocean Engineering, 51, 129-141.

Mendes, A.C., Kolodziej, J.A., \& Correia, H.J.D. (2003). Numerical modeling of wave-current loading on offshore structures. International Conference on Fluid Structure Interaction, 2, 85-96. Cadiz, Spain.

Mirzaei Sefat, S. \& Ketabdari, M.J. (2007). Dynamic analysis of interaction between linear waves and spar floating platform. 9th National Symposium of Marine Industries.

Mohseni Armak, S.M., \& Gharebaghi, A.R. (2012). Effect of HEAVE plates on the dynamic response of Amirkabir semi-submersible platform. International Conference on Coasts, Ports and Marine Structures.

Ran, Z., Kim, M. H., Niedzwecki, J. M., \& Johnson, R. P. (1996). Responses of a spar platform in random waves and currents (experiment vs. theory). International Journal of Offshore and Polar Engineering, 6(1).

Ray, J. (2000). WAMIT-MOSES Hydrodynamic analysis comparison study. New York Hull Engineering Department, USA.

Teng, B., \& Kato, S. (1999). A method for second-order diffraction potential from an axisymmetric body. Ocean Engineering, 26(12), 1359-1387.

Teng, B., \& Kato, S. (2002). Third order wave force on axisymmetric bodies. Ocean Engineering, 29(7), 815-843.

Wilson, J. F. (Ed.). (2003). Dynamics of offshore structures. John Wiley \& Sons. 